health. Nose revealed no obstructive mass and the mucous membrane appeared normal. The incisional scar over the right tear sac was healthy in appearance and there was no evident recurrence of the growth. Patient no longer complained of watering.

Until the patient has been followed for a much longer period of time the results of the treatment administered cannot be determined.

\title{
REFERENCES
}

1. Penman, G. G. and Wolff; E.-Primary tumours of the lacrimal sac. Lancet, Vol. II, pp. 1325, 1938 . Reviews the literature.

2. SPRATT, G. N.-Carcinoma of the lacrimal sac; report of a second case. Arch. Ophthal., Vol. XXIV, pp. 1237-1243, 1940.

\section{A CASE OF RUPTURE OF A RETINAL CYST CAUSING RETINAL DETACHMENT}

BY

\author{
Major C. DEe Shapland \\ R.A.M.C.
}

- CASES of retinal detachment clearly due to the spontaneous rupture of a retinal cyst are not common and hence this case is deemed worthy of placing on record, especially so as it clearly showed that a retinal dialysis or disinsertion can be produced by such a rupture.

J. S., aged 28 years, a private of the 8th Black Watch, was sent to the Ophthalmic Department of the Royal Victoria Hospital, Netley. on September 18, 1943, on account of failirg vision in the right eye noticed during the previous six weeks. The acuity of his right eye had been recorded as $6 / \dot{6}$ unaided on his examination by a civilián medical board on April 20,1940, and he was placed in Grade 1, being subsequently re-examined on May 16, 1940, and placed in Army Category $\mathrm{Al}$. He was re-examined medically on June 4 and November 13.19+2, and no change made in his category. On August 2, 194.3, the day before J. S. had first noticed the right vision to be misty, he had felt a sudden. sharp, shooting pain lasting some two to three minutes in the region of the right temple " just where the veins are". and felt giddy and faint. He was marching out of canp at the time in full equipment and wearing a steel helmet. He did not, however, report this occurrence and the subsequent blurring of his right vision to his unit M.O. untíl September 17, 1943.

On examination on September 20,194.3, the right eye was white, there were no keratic precipitates, the pupil was active and tension normal; a few coarse vitreous opacities were present below. Extending from 6.30 to 11 o'clock temporally was a flat detachment of the retina of recent origin with the macula involved, central 


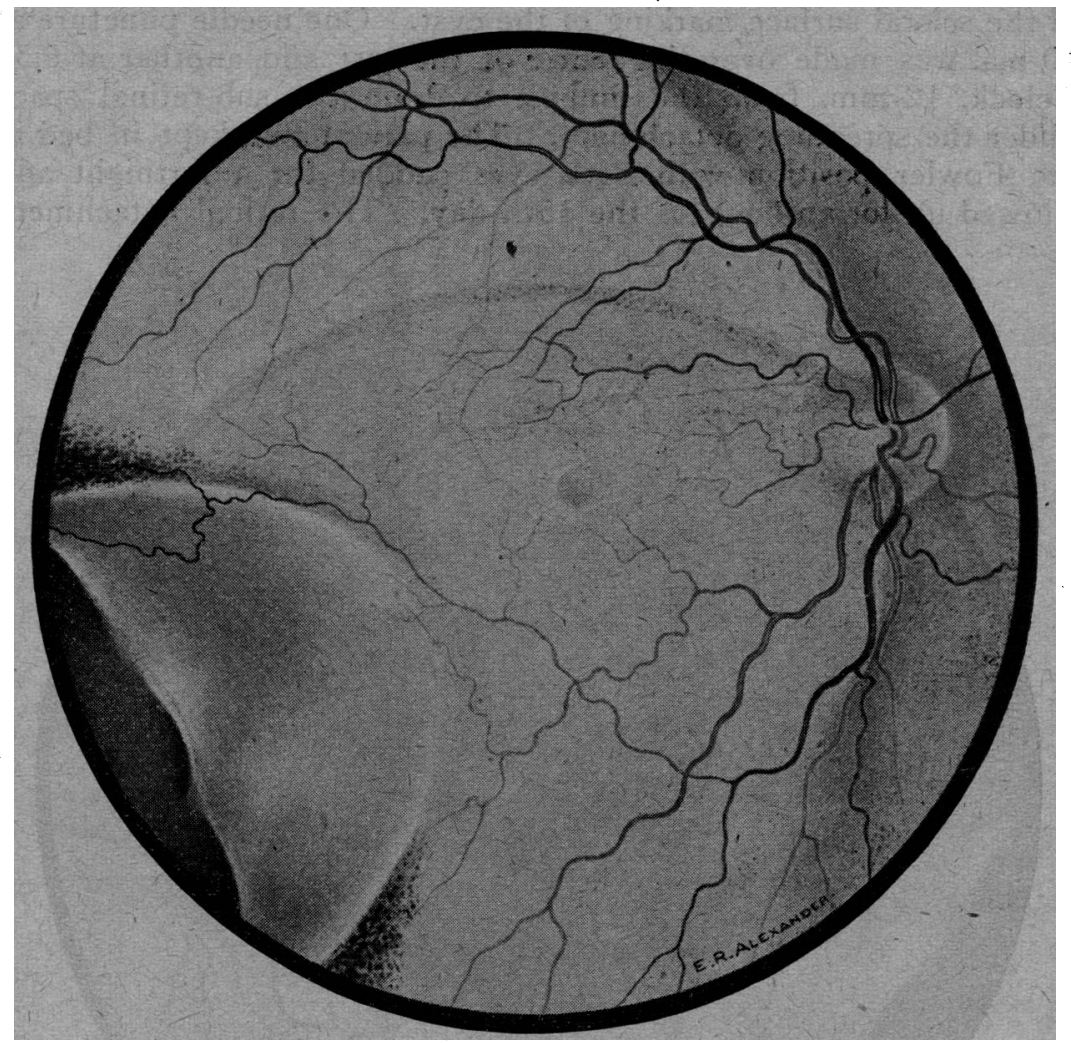

FiG. 1.

vision being reduced to $3 / 60$, not improved. At the $7-9$ o,clock periphery a prominent, thin-walled retinal cyst was present with ragged dialysis extending from 7.30-9 o'clock. The interesting. feature exhibited in this case was a linear band of retino-choroidal pigmentary disturbance delimiting the periphery of the cyst above and below. This disturbance was such as is usually seen at the high water mark of static retinal detachments of long standing. That the cyst was of considerable chronicity can therefore safely be inferred: The wall of the cyst had evidently ruptured peripherally at, or just behind, the ora serrata and so produced a ragged dialysis of the retina which had initiated a spreading detachment over the temporal half of the fundus in the usual way (Fig. 1). The left eye showed no symmetrical cyst or dialysis, the fundus being quite normal and its vision standard unaided:

Operation was performed on September 24, 1943, under surface 4 per cent. cocaine and sub-Tenon's capsule 4 per cent. novocaine anaesthesia. The external rectus was detached and a barrage of surface diathermy applications at $70 \mathrm{ma}$. placed round the periphery 
of the scleral surface marking of the cyst. One needle puncture at 40 ma. was made over the centre of the cyst and another at 6,30 o'clock, $12 \mathrm{~mm}$. from the limbus, to drain the sub-retinal space under the spreading detachment. The patient was kept in bed in the Fowler position with both eyes padded for a fortnight and allowed up for an hour on the 15 th day. The retinal detachment

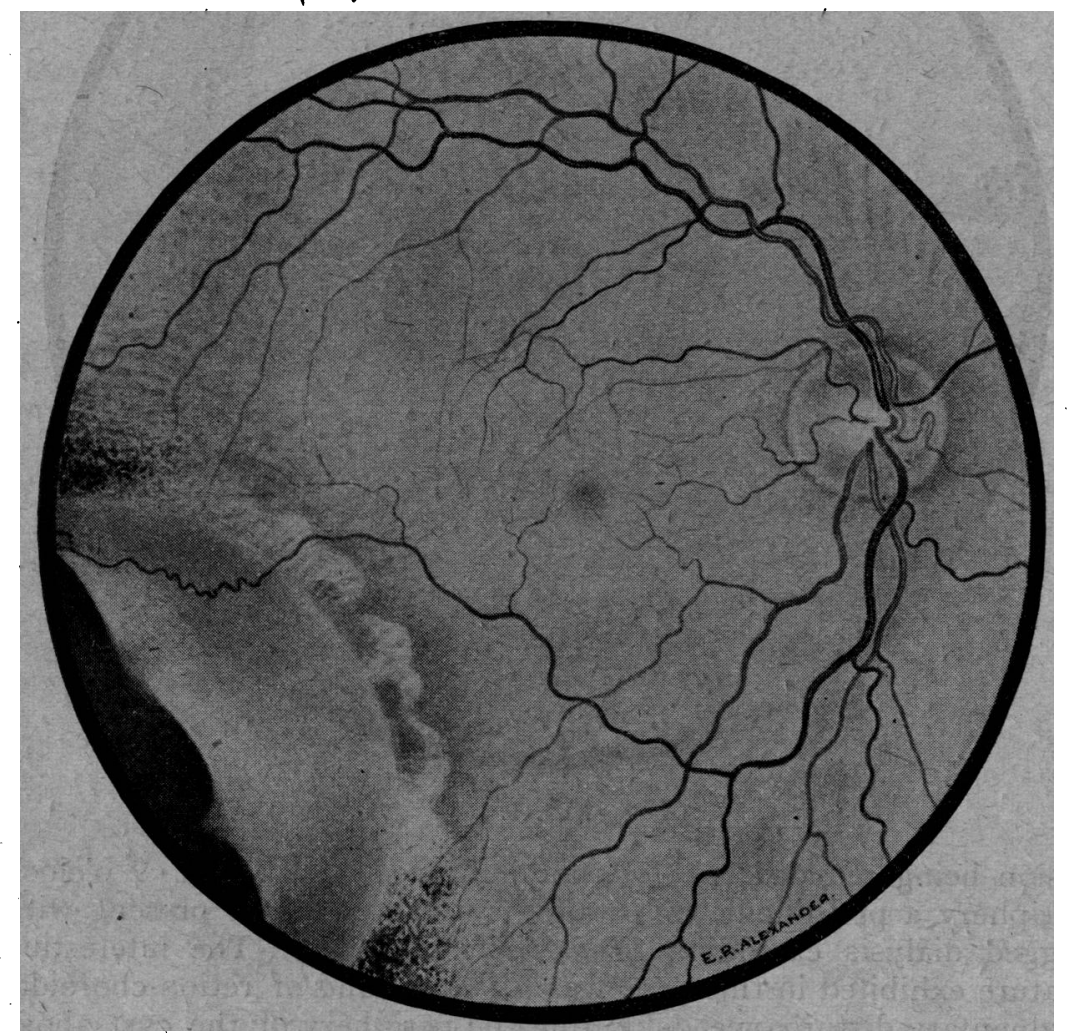

FIG. 2.

went back and the fundus appearance on the 25 th day after operation is shown in the drawing (Fig. 2).

The cyst was smaller and outlined on its inner side by a zone of diathermy reactions. The contraction of the latter had appeared to-pull down the wall of the cyst and so cause the whole to shrink somewhat. The dialysis, on the other hand, was still clearly visible and open. The retina was in place, central vision 6/24 partly, and the field full except for a defect on the nasal side corresponding to the diathermy reactions and the remains of the cyst.

The interest of this case, in my opinion, is that it clearly demonstrated three important facts. First, as I had long 
suspected, that a retinal dialysis can definitely be produced by the rupture of a peripheral cyst or cysts of the retina. Secondly, that little or no trauma, direct or indirect, can occasion their rupture. Thirdly, and most important, that a spreading detachment of the retina can be initiated by such a rupture, presumably through the inter-retinal space being opened up and invaded by the fluid portion of the vitreous, which, having passed through the rupture in the cyst wall, proceeds to break down any adhesions which may have formed along its periphery. Such adhesions were evidently present in this case as evidenced by the pigmentary disturbance in the retina at the upper and lower margins of the cyst, but these were not evident nasally and it therefore seems most probable that the inter-retinal space was opened into in this situation and the spreading detachment so started.

Simple cysts of the retina of the type under discussion are relatively rare. Ridley ${ }^{1}$ stated that a cystic detachment of the retina occurred in something like 3 per cent. of cases of detachment, a figure which in my experience is perhaps a little high. Peripheral cystic degeneration of the retina, however, is extremely common and presumably the type of cyst present in this case is derived

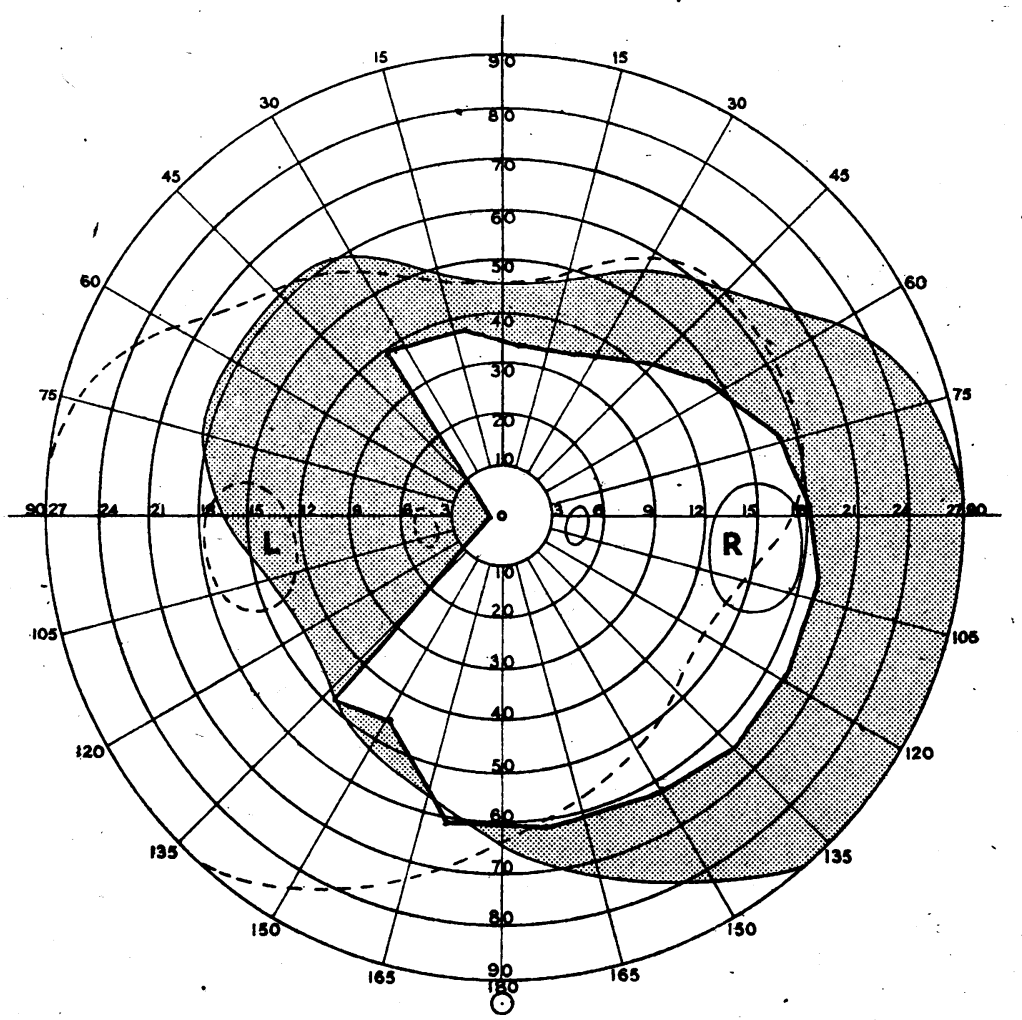




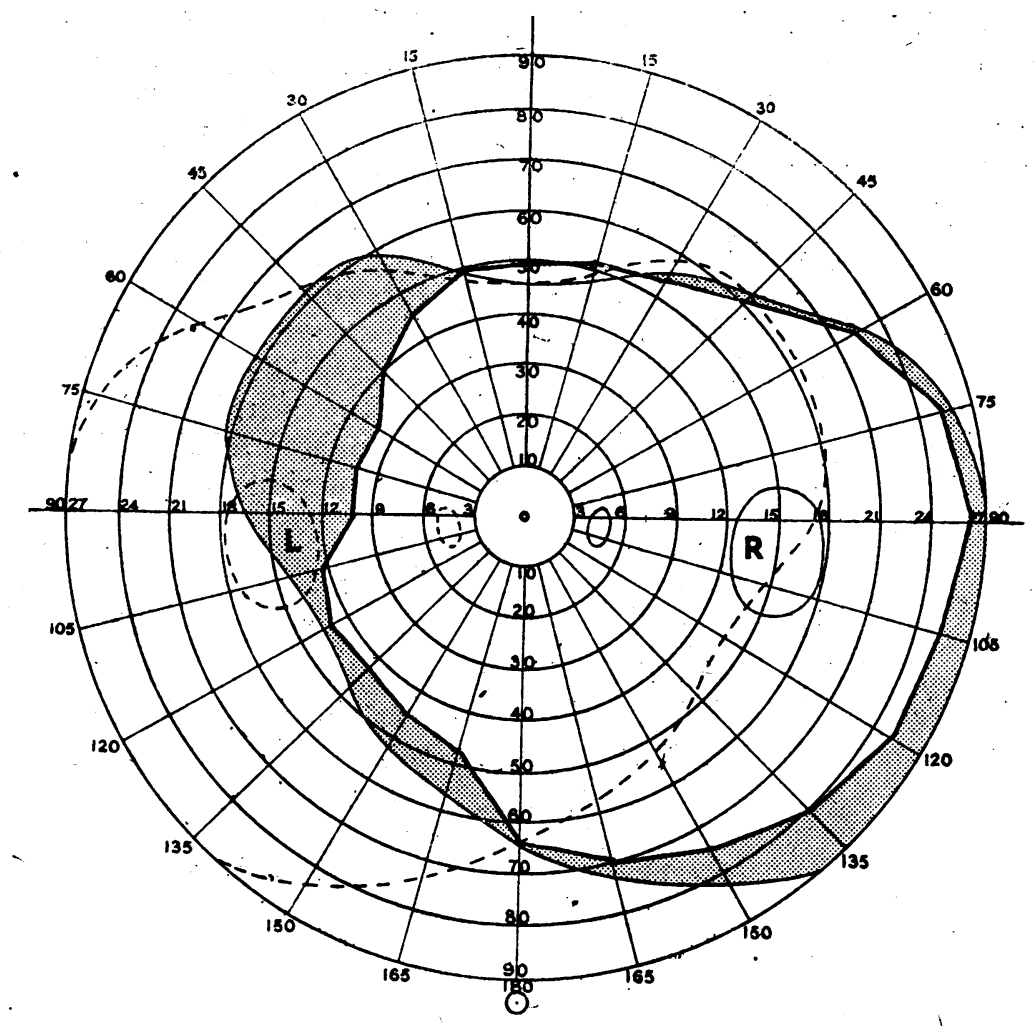

from a further development of this condition; pathologically it is essentially degenerative affecting the nervous elements of the retina. Cystic spaces usually first appear in the inner nuclear layer, and as they grow larger the layers of the retina are pushed aside and the nervous elements degenerate whilst the fibres' of Müller become elongated and often hypertrophied. Such a cyst may eventually occupy the entire thickness of the retina being bounded merely by glial tissue and the internal and external limiting membranes. Further increase in size, presumably by an active accumulation of fluid, will cause the cyst wall to bulge internally towards the vitręous where it is least supported and a rupture would naturally tend to occur where the wall is likely to be thinnest, i.e. at or just behind the ora serrata.

It would therefore appear wise to operate upon these cases of simple peripheral cyst of the retina provided a visible and complete demarcation line of retino-choroidal pigmentary disturbance, indicative of a sealing off of the inter-retinal space, is not present all along the inner (disc side) periphery of the cyst. Goulden ${ }^{2}$ called attention to this type of detachment and advised operative treatment, mentioning that "if a diathermy operation is performed on the 
sclera overlying the cyst and the cyst is then evacuated, progress seems to be uniformly good." It would appear, however, to be a safer procedure in all cases and more especially if the cyst has ruptured, to place a ring of diathermy surface applications over the retina all along the inner periphery of the cyst, in addition to those over the cyst itself, before puncturing the latter. In this way the inter-retinal space should become securely sealed off and the risk of a spreading detachment obviated, even if through stretching of the cyst wall snug apposition of the latter to the underlying choroid is prevented.

\title{
REPERENCES
}

1. RIDLEY (1935).-Brit. Jl. Ophthal., Vol. XIX, p. 101.

2. GouldeN (1935).-Trans. Ophthal. Soc. U.K., Vol. LV,p. 407.

\section{CONGENITAL PARALYSIS OF BOTH EXTERNAL RECTI TREATED BY TRANSPLANTATION OF EYE MUSCLES*}

\author{
BY \\ JOHN A. MAGNUS \\ YORK
}

Miss P. W., aged 12 years. This child has a gross spinal deformity (kyphosis, scoliosis and torticollis) from birth. $\mathrm{X}$-ray report at the age of 3 years (1933): Spina bifida occulta, involving all the cervical vertebrae and some of the upper dorsal, left-winged scapula.

I saw the child first on October 28, 1942, when I diagnosed: Bilateral abducens paralysis, right marked hyperphoria due to overacting right inferior oblique. (See Fig. 1). The vision is $6 / 6$ in each eye, and the fundi are normal. The child has no binocular vision. She suppresses the right image.

On January 16, 1943, the left eye was operated upon under a general anaesthetic. I performed a recession of the left internal rectus $(5 \mathrm{mms}$.) which was very contracted and thick. Following O'Connor's technique, I made a semi-circular incision in the conjunctiva around the temporal half of the cornea, about $10 \mathrm{mms}$. away from the limbus, the incision extending from "12 to 6 oclock." I exposed the superior and inferior recti, and split the tendons longitudinally for about $12 \mathrm{mms}$. with an old Graefe knife. A double-armed catgut suture was then run through the outer halves of the superior and inferior recti, and firmly tied. The segments were now dissected off their insertions and sewn beneath the

- Received for publication, January 19, 1944. 